\title{
Professional Sports and Empathy: Relationship Between Professional Futsal Players' Tendency Toward Empathy and Fouls
}

Authors' contribution:

A) conception and design of the study

B) acquisition of data

C) analysis and interpretation of data

D) manuscript preparation

E) obtaining funding

\section{Gülfem Sezen-Balçikanli ${ }^{\mathrm{A}, \mathrm{C}, \mathrm{E}}$, Mehmet Sezen $^{\mathrm{B}, \mathrm{D}}$}

Gazi University, Turkey

\begin{abstract}
The objective of this study is to determine the correlation between the professional futsal players' (futsallers') empathic tendency and the numbers of the cards they are shown and the fouls they commit. Empathy was assessed through a Turkish version of Interpersonal Reactivity Index-IRI. The original IRI takes as its starting point from the notion that empathy consists of a set of separate but related constructs, and seeks to provide measures of dispositional tendencies in several areas. The instrument contains four (seven-items) subscales, each tapping a separate facet of empathy. The items are scored on a 5-point Likert scale, with 0 (does not correspond at all to me) and 4 (corresponds exactly to me) serving as extreme points. Research group is composed of total 76 professional male futsal players who took part in Efes Pilsen Futsal League games with 7 teams from Ankara region. Age averages of all the participants were between the ages of 18 and 38 and their age average range was from 24 to 26. As a statistical method in the assessment of the research data; in order to examine the correlation between the general average, standart deviation, mean per team, standart deviation and professional futsal players' empathy levels and the number of the cards they are shown (yellow/red) and their fouls, Spearman Rank Correlation was utilized. The results obtained demonstrate that there is a relationship between empathy and yellow/red cards and fouls. It is considered that the empathy practices to be developed for the sportspersons will develop perspective taking and interpersonal communication between them, enhance moral viewpoint and moral attitudes in sports in them, and reduce the aggressive behaviours and self-seeking actions.

Professional sports, empathy, futsal, futsal players, fouls
\end{abstract}

\section{Introduction}

Empathy is one of the factors that are specifically pointed out in the case of development of moral values. For the individuals to have good behaviours and character, their empathic skills are of great value. Do athletes who have an empathic orientation exhibit more good manners than those who do not? The fouls committed by athletes against their opponents and the cards they are shown for this reason or similar reasons can be defined in general as unsportsmanlike conducts. Is there a relationship between the unsportsmanlike 
conducts and a sportsperson's tendency toward empathy? Taking the above questions into consideration, objective was set in this study to determine the correlation between the professional futsal players' (futsallers') empathic orientations and the numbers of the cards they are shown and the fouls they commit.

The concept of empathy has been studied by numerous researchers (Greif \& Hogan, 1973; Rogers, 1975; Hoffman, 1976; Davis, 1983; Dökmen, 1988; Eisenberg \& Strayer, 1990, Hoffman, 1990) since its first use as "Einfühlung" by the German aesthetes as of the end of the $19^{\text {th }}$ century (Wispe, 1990; Vischer, 1994). In recent years, there have been empathy-related studies such in the different fields of science as neuroscience, psychology, and social psychology (Eisenberg \& Strayer, 1990; Davis, 1996; Decet \& Ickes, 2009; Chambers \& Davis, 2012). However, when the literature is examined, it is observed that the number of the studies in terms of relation between sports and empathy is few (Kalliopuska 1987; Shields \& Bredemeier, 1994; Yıldıran, 2005; Kavussanu, Stamp, Slade \& Ring, 2009; Sezen, 2009; Sezen, 2010; Sezen, 2012; Garcia-Lopez \& Gutierrez 2013; Sevdalis \& Raab, 2014). But it is quite important to understand empathy and research the relationship between sports and empathy. If we start by defining empathy, Hoffman (1990, p. 48) defines empathy as "an effective response more appropriate to someone else's situation then to one's own'. According to Davis (1983) empathy in the broadest sense refers to 'the reactions of one individual to the observed experiences of another" (Davis, 1983, p. 113). Eisenberg and Strayer (1990) define empathy as 'an emotional response that stems from another's emotional state or condition and that is congruent with the other's emotional state or condition' (Eisenberg \& Strayer 1990, p. 5).

According to Kalliopuska (1990), in holistic perspective, empathy is considered to be a coherent process within an organism and to consist of physiological, kinaesthetic, affective (and Motivational), as well as cognitive components. There have been various studies in regards to measurement of empathy for many years (Dymond, 1949; Kerr \& Speroff, 1954; Hogan, 1969; Mehrabian \& Epstein, 1972, Dökmen, 1988). One of them is Interpersonal Reactivity Index developed by Davis. Davis (1980) developed an individual difference measure of empathy (the Interpersonal Reactivity Index, IRI) based on such a multidimensional approach. Rather than treating empathy as a single unipolar construct, the rationale underlying the IRI is that empathy can best be considered as a set of constructs related in that they all concern responsivity to others but are also clearly discriminable from each other (Davis, 1980). The constructs belonging to the IRI are as follows. Empathic concern inquires about respondents' feelings of warmth, compassion, and concern for others, while the personal distress scale measures the personal feelings of anxiety and discomfort that result from observing another's negative experience (Davis, 1980, p. 2). Personal distress refers to feelings of anxiety, distress, and unease with intense or crisis situations (Davis, 1983, p. 169). Perspective taking, on its face, seems to reflect an ability or proclivity to shift perspectives - to step "outside the self" - when dealing with other people (Davis, 1980, p. 11-12). This ability should allow an individual to anticipate the behaviour and reactions of others, therefore facilitating smoother and more rewarding interpersonal relationship (Davis, 1983, p. 115). Fantasy appears to tap the tendency to imaginatively transpose oneself into fictional situations (e.g., books, movies, daydreams) (Davis, 1980, p. 11).

When the relationship between sports and empathy is concerned, very little is known when it comes to the links between sport experience and empathy. Nevertheless, it is possible to say that sportive experience reduces empathy toward others. Emphasizing with the opponent may contradict with the objective of "success" and empathizing with a teammate might harm focusing on personal performance. Moreover, some coaches deliberately do not want their sportspersons to worry about their opponents. The study on 1381 Finnish male and female baseball players whose ages ranged between 8 and 16 partially supports the abovementioned issue (Shields \& Bredemeier, 1994). Kalliopuska (1987) found in this study that as the period of playing baseball by the sportspersons increased, they exhibited lesser sensitivity, an element of empathy. No change was observed in terms of their empathy levels but it was observed that the female players were more sensitive than the male ones (Kalliopuska, 1987; Shields \& Bredemeier, 1994). As far as the studies on empathy and sports are concerned, the results of the study of Kavussanu, Stamp, Slade, and Ring (2009) indicated that female individuals were seen to display higher levels of empathy than males, which indicated that there was a difference in the levels of empathy in terms of gender in antisocial behaviours. In the study 
of Sevdalis and Raab (2014) where they made a summary of the main findings from various research studies in which empathy measurements are employed in the domains of sport, exercise and the performing arts, the overall findings are examined with regard to studies related to motor-performances. Issues such as interdisciplinary dialog, implications for research, and applied practice are also discussed with a view to providing a more general perspective of the domains mentioned above. With respect to the results of the study of Garcia-Lopezand Gutierrez (2013), the most important conclusion that we can draw from this study is that Sport Education has a great potential in terms of educating children. However, this potential needs to be checked with various types of teaching models and approaches. The model used in the study seems to have a great impact on the ability of children to understand situations from different perspectives, which can be deduced from the fact that empathy and assertiveness were developed as a result of a single treatment prepost-test design. Therefore, one can reach the conclusion that Sport Education was found to be an effective tool for developing social and citizen competency, as stipulated in the Spanish curriculum. Nonetheless, there seems to be a need for further studies which look at the effect in real situations (Garcia-Lopez \& Gutierrez, 2013).

Studies on empathy reveal the importance of empathy training for individuals. For instance, Kavussanu et al. (2009) found that soccer players who had lower empathic skills tended to show more antisocial behaviours. Furthermore, empathic concern and perspective taking are known to facilitate prosocial behaviours. According to Hogan, moral development can be conceptualized and moral conduct explained in the light of five dimensions (moral knowledge, socialization, empathy, autonomy, and a dimension of moral judgment), each defined by a separate measure (Greif \& Hogan, 1973). Objective through empathy training is to ensure that the other is understood better and a permanent and positive attitude is developed to him/her. Understanding eliminates prejudices, prevents aggression, and enhances social attitudes (Yıldıran, 2005). Lickona (1991), in our society today we may be witnessing a decline in empathy.

While lack of empathy is one of the biggest problems of our society, it is observed that sportsmen prefer to play sport games with similar situations in sports. Foul play is all of the unfair behaviors. Kosiewicz (2011), believes that fouls in sport, particularly those committed by athletes during competition, will always be inconsistent with the accepted rules of the game, that is, with the official regulations. Fouls will also always influence - in more or less annoying, depressing, painful or even tragic ways - the fate and the health of athletes. In another study, foul play is strongly opposed by supporters of the fair play principle, by those who do not regard sports competition as a phenomenon that can be considered independently beyond moral good and evil (Kosiewicz, 2010).

It is considered that the empathy practices to be developed for the sportspersons will develop perspective taking and interpersonal communication between them, enhance moral viewpoint and moral attitudes in sports in them, and reduce the aggressive behaviours and self-seeking actions. According to Kosiewicz (2011), foul play in sports has so many forms and will probably never lose its popular and sometimes spectacular character. Knowing that, everything should be done to protect players from bothersome health, interpersonal, and cultural disablements resulting from foul play. With this in mind, thepurpose of the study is to draw an overall picture by scrutinizing the professional futsal players' perspective taking, empathic concern, fantasy and personal distress tendencies, and to see whether there is correlation between empathy tendency and the numbers of the yellow cards, red cards, and fouls by ascertaining the tendency toward empathy in professional sports.

\section{Method}

\section{Instrumentation}

Empathy was assessed by a Turkish version of Interpersonal Reactivity Index-IRI. The original IRI takes as its starting point from the notion that empathy consists of a set of separate but related constructs, and seeks to provide measures of dispositional tendencies in several areas. The instrument contains four (seven- 
items) subscales, each tapping a separate facet of empathy. The items are scored on a 5-point Likert scale, with 0 (does not correspond at all to me) and 4 (corresponds exactly to me) serving as extreme points. The perspective taking (PT) scale measures the reported tendency to spontaneously adopt the psychological point of view of others in everyday life (I sometimes try to understand my friends better by imagining how things look from their perspective.). The empathic concern (EC) scale assesses the tendency to experience feelings of sympathy and compassion for unfortunate others (I often have tender, concerned feelings for people less fortunate than me.). The personal distress (PD) scale taps the tendency to experience distress and discomfort in response to extreme distress in others (Being in a tense emotional situation scares me.). The fantasy scale (FS) measures the tendency to imaginatively transpose oneself into a fictional situation (When I am reading an interesting story or novel, I imagine how I would feel if the events in the story were happening to me.) (Davis, 1980).

Interpersonal Reactivity Index-IRI was translated into Turkish by Engeler (2005). Undergraduate students from two universities completed Interpersonal Reactivity Index for the pilot studies. After pilot studies, Interpersonal reactivity Index was given to 214 volunteered undergraduate students (95 male, 116 women, 7 neglected their gender). Majority of them were single (98.1\%) and their ages ranged from 18 to 27 $(M=20.96, S D=1.52)$. Mean inter-item correlations and internal consistencies (standardized item alphas) of subscales of Interpersonal Reactivity Index were computed. Corrected item-total correlations were reported as a result of item analysis. Intercorrelations of subscales and their correlations with gender were reported to evaluate their preliminary validity. In order to assess test-retest reliabilities of the four subscales, an independent sample of undergraduate students $(\mathrm{N}=40)$ completed Interpersonal Reactivity Index twice with the interval of 20-24 days and test-retest reliabilities were computed. Internal consistencies of all four subscales were satisfactory (0.60-0.76). Mean inter-item correlations showed that subscales had a homogenous content $(0.17-0.32)$. In item analysis, three items revealed relatively a poor performance. However, the means of corrected item-total correlations were high for all the subscales (0.32-0.49). Intercorrelations of subscales were consistent with the relevant literature. Test-retest correlations were in an acceptable range (0.66-0.80). Subscales of Interpersonal Reactivity Index had excellent psychometric properties. Although three items performed relatively poorly, these items contributed to the whole subscales. In addition, intercorrelations of subscales and their correlations with gender were consistent with expectancies and the literature (Engeler, 2005).

\section{Participants}

Research group is composed of total 76 professional male futsal players who took part in Efes Pilsen Futsal League games with 7 teams from Ankara region. Age averages of all the participants were between the ages of 18 and 38 and their age average range was from 24 to 26. The scale was administered to the 76 male participants prior to the competitions by the researcher accompanied by their coaches throughout the tournament. All the participants stated that they had played soccer before they started playing futsal and their average of sport-played years professionally ranged from 8 to 10 years.

\section{Procedure}

The items collected were checked by the researcher and the imperfectly or wrongly-filled ones were kept out of the study. Later on, those that were found to be valid and acceptable were transferred to computer environment. As a statistical method in the assessment of the research data;in order to examine the correlation between the general average, standart deviation, mean per team, standart deviation and professional futsal players' empathy levels and the number of the cards they are shown (yellow/red) and their fouls, Spearman Rank Correlation was utilized. 


\section{Results and discussion}

The purpose of the study is to identify the tendency toward empathy of professional futsal players and whether there is a correlation between empathy tendency and the numbers of the yellow cards, red cards, and fouls. Accordingly, averages of the futsal players' tendency toward empathy (Table 1); numbers of the yellow/red cards and fouls (Table 2); and the results of the correlation between the numbers of the yellow cards, red cards, and fouls and empathy tendency (Table 3) are provided. Futsal players' highest average belongs to the empathic concern sub-dimension while their lowest averages correspond to the personal distress dimension.

Most sport participants commonly experience failure, and if empathy for the opponent's failures and losses is not particularly adaptive in this context, empathy for one's teammates who fair to perform effectively is probably quite common and socially adaptive (Keleiber \& Roberts, 1981, p. 116).

Table 1. General and Team-based average and standard deviation values

\begin{tabular}{|c|c|c|c|c|c|c|c|c|c|c|c|c|c|c|c|c|}
\hline & \multicolumn{2}{|c|}{ Team 1} & \multicolumn{2}{|c|}{ Team 2} & \multicolumn{2}{|c|}{ Team 3} & \multicolumn{2}{|c|}{ Team 4} & \multicolumn{2}{|c|}{ Team 5} & \multicolumn{2}{|c|}{ Team 6} & \multicolumn{2}{|c|}{ Team 7} & \multicolumn{2}{|c|}{ Total } \\
\hline & $\sum_{\Sigma}^{\Xi}$ & $\vec{n}$ & $\sum_{\bar{\Xi}}^{\Xi}$ & $\vec{n}$ & $\sum_{\Sigma}^{\Xi}$ & $\ddot{n}$ & 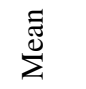 & D & $\sum^{\mathbb{E}}$ & in & 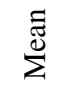 & $\vec{n}$ & 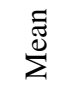 & $\ddot{n}$ & $\sum_{\Sigma}^{\Xi}$ & $\vec{n}$ \\
\hline $\mathrm{n}$ & 3.07 & 0.54 & 2.45 & 0.75 & 2.55 & 0.50 & 2.11 & 0.54 & 2.54 & 0.54 & 2.38 & 2.33 & 2.45 & 0.61 & 2.50 & 0.61 \\
\hline $\begin{array}{l}\text { Perspective } \\
\text { taking }\end{array}$ & 2.60 & 0.41 & 2.20 & 0.79 & 2.18 & 0.35 & 1.95 & 0.59 & 2.25 & 0.33 & 2.33 & 0.35 & 2.36 & 0.39 & 2.26 & 0.49 \\
\hline & 1.80 & 0.58 & 1.74 & 0.54 & 1.87 & 0.44 & 1.87 & 0.25 & 2.38 & 0.49 & 2.22 & 0.38 & 2.23 & 0.48 & 2.04 & 0.51 \\
\hline $\begin{array}{l}\text { Personal } \\
\text { distress }\end{array}$ & 1.53 & 0.41 & 1.76 & 0.45 & 1.65 & 0.70 & 1.97 & 0.51 & 2.11 & 0.43 & 2.14 & 0.32 & 2.05 & 0.38 & 1.91 & 0.50 \\
\hline
\end{tabular}

Source: own study.

Empathic thought is the reaction of the individual by feeling sad and uncomfortable when he/she witnesses sadness of others. Empathic thought reflects the care and sensitivity toward others (CulottaHackenberg, 2002). According to Hoffman (1990) who asserts that the roots of morality can be found in empathy, showing empathy towards the potential victims who are in pain or danger or deprivation and sharing their problems is what direct people to help such persons. Beyond this direct relationship between empathy and self-sacrifice is encountered in the personal relations, Hoffman believes that the empathic sense capacity; that is to say, the ability to put oneself in the shoes of others, directs persons to followsome moral principles (Hoffman, 1990; Goleman, 1998). Professional futsal players have the highest average in the subdimension of empathic thought. Perspective taking scale measures the reported tendency to spontaneously adopt the psychological point of view of others in everyday life (Davis, 1996, p. 57). It is anticipated that there will be a strong correlation between that higher perspective taking score and better social functioning and higher self-esteem. Perspective taking ability is expected to allow an individual to anticipate the behaviour and reaction of others, therefore facilitating smoother and more rewarding interpersonal relationship (Davis, 1983, p. 115). According to Trötschel, Hüffmeier, Loschelder, Schwartz, and Gollwitzer (2011), perspective taking does not lead to empathic feelings. However, they can be employed in egoistic terms: A chess player, for instance, may take an opponent's perspective for egoistic reasons thus focusing on the opponent's thoughts, motives, and/or strategy. Shields and Bredemeier state (1994) that in the event that a player who plays racquetball recognizes he/she is much more talented than his/her opponent, his/her empathy skills may point out a requirement for recreating the circumstances for a real competition (a catchas-catch-can competition) and for redefining the match. It is possible to say that if the athletes are provided with the skill of perspective taking, it will be possible to bring a different viewpoint into the match and that sportspersons with high self-esteem and better social functioning will be acquired. According to Davis, (1983, p. 115) fantasy scores will exhibit a relationship with measures of emotionality. Fantasy scale measures "the tendency to imaginatively transpose oneself into fictional situations" (Davis, 1996, p. 57). When the professional futsallers' fantasy scores are examined, the average appears to be 2.04 and when such 
scores are related with emotionality, it is possible to assert that the averages taken on by the futsallers are low. Finally, personal distress items were identified, which indicated that the respondent experienced feelings of discomfort and anxiety when witnessing the negative experiences of others (Davis, 1980, p. 6). Results of the research exhibit that the professional futsallers took on the lowest average in the dimension of personal distress.

Empathizing with opponents may be counterproductive to the goal of winning, and empathizing even with teammates may detract from focused concentration on personal performance. Furthermore, many coaches deliberately discourage concern for opponents (Bredemeier \& Shields, 1994, p. 107). Particularly in today's score-based professional sports, the understanding of "winning at all cost" causes the sportspersons to have low tendency toward empathy. This condition is observed more manifestly in the team sports with close contact (Sezen, 2009; Sezen, 2010; Kavussanu, Stamp, Slade, \& Ring, 2009).

Table 2. Numbers of yellow- red card, foul and goals of professional futsal players

\begin{tabular}{lccccccc}
\hline & Team 1 & Team 2 & Team 3 & Team 4 & Team 5 & Team 6 & Team 7 \\
\hline Yellow card & 7 & 4 & 13 & 8 & 3 & 6 & 3 \\
Red card & - & - & 2 & 3 & 1 & 1 & - \\
Number of fouls & 51 & 38 & 48 & 42 & 23 & 23 & 22 \\
\hline
\end{tabular}

Source: own study.

Table 2 was given above in order to provide information the numbers of the players' cards and fouls in general. Accordingly, the team that is shown most of the yellow cards is "team 3" and the team that is shown most of the red cards is "team 4 " and the team that has most fouls "team 1."

Table 3. Spearman rank correlation values for the professional futsal players

\begin{tabular}{lllll}
\hline & Empathic concern & Perspective taking & Fantasy & personal Distress \\
\hline Yellow card & 0.082 & -.0518 & -0.376 & -0.609 \\
Red card & -0.359 & $-0.774^{*}$ & 0.305 & 0.170 \\
Foul & 0.473 & -0.200 & -0.611 & $-0.855^{*}$ \\
\hline
\end{tabular}

Source: own study.

When Table 3 is analysed, it is seen that there is a moderate level and negative correlation at -0.518 between Yellow Card and Perspective Taking tendency and that Fantasy tendency is at -0.376 and personal distress tendency is at -0.609 with moderate level and negative correlation. When red cards are scrutinized, Empathic Concern tendency is weak at -0.359 and has negative correlation while Perspective Taking is "meaningful" at the level of -0.774 to 0.05 in high level and with negative correlation. Fantasy and Personal Distress exhibit weak and positive correlations with the red cards (respectively, 0.305; 0.170). When the fouls committed by the futsallers and their empathy tendencies are scrutinized, they exhibit a correlation, which is weak and positive at 0.473 in terms of empathic concern tendency; very weak and negative at 0.200 in terms of perspective taking tendency; moderate and negative fantasy tendency -0.611 ; high at -0.855 and "meaningful" at the negative direction at 0.05 in terms of fantasy.

The results obtained demonstrate that there is a relationship between empathy and yellow/red cards and fouls. When the studies conducted are analyzed, it is seen that significant negative correlations have been found between empathy and antisocial behaviourin children and adolescents (Garaigordobil, 2009; Garaigordobil, Álvarez \& Carralero, 2004). In Garaigordobil's study, (2009) the research reported here highlights the fact that empathy is an important factor in the process through which the individual develops both the patterns of thinking and behaviour in accordance with social norms, and the connections of empathy to a highly relevant structural personality construct such as self-concept. Empathy appears to be closely related to antisocial behaviour in boys and to prosocial behaviour in both gender, and is crucial to understanding social behaviour. In Rumble, Paul, Lange and Parks' research, (2010), the purpose was to 
examine the ability of empathy to effectively motivate increased cooperative behaviour in order to reduce or eliminate the detrimental effects of noise on sustained cooperative interaction. The results demonstrate that empathy-motivated cooperation helps individuals to overcome the detrimental effects of negative noise, but it is not as successful in overcoming intentional noncooperation over the long term. Another study suggests that empathy evokes an altruistic motive to reduce the victim's suffering rather than an egoistic aversivearousal reduction motive (Stocks, Lishner \& Decker, 2009).

Despite the fact that the number of studies regarding empathy in sports environment is few, limited number of studies demonstrates that sportive interactions, especially in team sports, are established on coordinating the movements and they require an ability of understanding the game by way of multidimensional resources in line with such coordination. For example, a player is required to envisage what a teammate of him/her is going to do in some certain cases. This circumstance includes the mixed coordination of different viewpoints of a game. Successful implementation of branches that contain varied playing strategies will no doubt increase the rate of perspective-taking ladder (Shields \& Bredemeier, 1994). In addition, increasing the tendency of sportspersons toward empathy will direct them toward pro-social behaviours, reduce their aggressive behaviours throughout the contest, and ensure that they will exhibit temperate manners in the case of defeat or victory. It is pointed out in the study conducted by Kavussanu et al. (2009) that the soccer players with low empathy skill exhibit more antisocial behaviours. In Sezen's study (2010) on professional soccer players, the fact that a positive relation between tendency toward sportspersonship and empathy is available was revealed.

\section{Conclusion}

Empathy helps individuals understand their points of interests, needs, and desires, as well as their sensitivities for others. All these issues are related with moral perception and moral behaviours. Persons with empathic skills can perceive the moral dimensions of events better (Miller, Bredemeier \& Shields, 1994). In this framework, empathy education to be provided to the sportspersons is important. In the literature, there are multiple studies demonstrating that empathic skill can be enhanced through education. The study conducted by Kalliopuska and Tiitinen (1991) yielded a result that the empathy programme used together with the techniques like painting and physical activities had increased the empathic skills of children. Studies on sports and empathy can be conducted in terms of different age groups and different branches. In particular, it is possible to pore over the fact that whether there is a difference between individual branches and team branches with regard to empathy. It is also possible that the cards shown, fouls, and the sportspersons' behaviours like prosocial and antisocial behaviours are observed throughout a league term and their relation with empathy can be scrutinized.

As a result, development of empathy that has both affective and cognitive nature; that is to say, a multidimensional nature; will provide positive outcomes for the sportspeople in respect of displaying different viewpoints, avoiding to take the opponent into account as an enemy, controlling the harsh and aggressive behaviours, and exhibiting temperate manners in the case of victory or defeat. This will positively affect the character development of the sportspersons who act as social models and protect the moral values in sports that we are losing at a fast pace.

\section{REFERENCES}

Chambers, J.R. \& Davis, M.H. (2012). The Role of the Self in Perspective-Taking and Empathy: Ease of SelfSimulation as a Heuristic for Inferring Empathic Feelings. Social Cognition, 30(2), 153-180.

Culotta-Hackenberg, L.S. (2002). Empathy Development and Its Relationship With Aggressive and Delinquent Behavior in Adolescents. (Doctoral Dissertation, Cleveland State University, 2002). Dissertation Abstracts International.

Davis, H.M. (1980). A Multidimensional Approach to Individual Differences in Empathy. JSAS Catolog of Selected Documents in Psychology, 10, 85. 
Davis, H.M. (1983). Measuring Individual Differences in Empathy: Evidence for a Multidimensional Approach. Journal of Personality and Social Psychology, 44(1), 113-126.

Davis, H.M. (1996). Empathy A Social Psychological Approach, $2^{\text {nd }}$. ed. USA: Westviewpress.

Decety, J. \& Ickes, W. (2009). The Social Neuroscience of Empathy. Massachusetts Institute of Technology, USA.

Dökmen, Ü. (1988). Empatinin Yeni Bir Modele Dayanılarak Ölçülmesi ve Psikodrama ile Geliştirilmesi /Empathine Based on a New Model and Development of Psychodrama/. Ankara Üniversitesi Eğitim Bilimleri Fakültesi Dergisi, 21(1-2), 155-190.

Dymond, R.F. (1949). A Scale For The Measurement Of Empathic Ability. Journal of Consulting Psychology, 13(2), 127-133.

Eisenberg, N. \& Strayer, J. (1990). Critical Issues in the Study of Empathy. In N. Esinberg, \& J. Strayer (Eds.), Empathy and Its Development (pp. 3-13). New York: Cambridge University Press.

Engeler A. (2005). Psikopati ve Antisosyal Kişilik Bozukluğu. Yayınlanmamış Doktora Tezi. İstanbul: İstanbul Üniversitesi.

Garaigordobil, M., Álvarez, Z. \& Carralero, V. (2004). Conducta Antisocial En Niños De 10 A 12 Años: Factores De Personalidad Asociados Y Variables Predoctoras /Antisocial Behavior in Children 10 to 12 Years: Associated Personality Factors and Predoctor Variables/. Análisis y Modificación de Conducta,30, 241-271.

Garaigordobil, M. (2009). A Comparative Analysis of Empathy in Childhood and Adolescence: Gender Differences and Associated Socio-emotional Variables. International Journal of Psychology and Psychological Therapy, 9(2), $217-235$.

García-López, L.M. \& Gutiérrez, D. (2013). The Effects Of A Sport Education Season On Empathy And Assertiveness. Physical Education and Sport Pedagogy, 1-16.

Goleman, D. (1998). Duygusal Zekâ Neden IQ’ dan Daha Önemlidir? / Why Emotional Intelligence is More Important than IQ? / Baskı. İstanbul: Varlık/Bilim.

Greif, B.E. \& Hogan, R. (1973). The Theory and Measurement of Empathy. Journal of Counseling Psychology, 20(3), 280-284.

Hoffman, M.L. (1976). Empathy, Role-Taking, Guilt, And Development Of Altruistic Motives. In T. Lickona (Ed.), Moral development and behavior: theory, research, and social issues. New York: Holt, Rinehart, \& Winston.

Hoffman, M.L. (1990). The Contribution of Empathy to Justice and Moral Judgment. In N. Esinberg, \& J. Strayer (Eds), Empathy and Its Development (pp. 47-80). New York: Cambridge University Press.

Hogan, R. (1969). Development of an Empathy Scale. Journal of Consulting and Clinical Psychology, 33(3), $307-316$.

Kalliopuska, M. (1990). Self-Esteem And Empathy As Related To Participation In The Arts Or Sports Activities. In The Self-Concept (pp. 121-132). Springer Berlin Heidelberg.

Kalliopuska, M. \& Tiitinen, U. (1991). Influence of Two Developmental Programmes on The Empathy and Prosociability of Preschool Children. Perceptual and Motor Skills, 72, 323-238.

Kalliopuska, M. (1987). Relation of Empathy And Self-Esteem to Active Participation in Finnish Baseball. Perceptual And Motor Skills, 65, 107-113.

Kavussanu, M., Stamp, R., Slade, G. \& Ring, C. (2009). Observed Prosocial and Antisocial Behaviors in Male and Female Soccer Players. Journal of Applied Sport Psychology, 21(1), 62-76.

Kerr, W.A. \& Speroff, B.J. (1954). Validation and Evaluation of the Empathy Test. The Journal of General Psychology, 50(2), 269-276.

Kleiber, D.A. \& Roberts, G.C. (1981). The Effects Of Sport Experience In The Development Of Social Character: An Exploratory Investigation. Journal of Sport Psychology, 3(2), 114-122.

Kosiewicz, J. (2010). Sport beyond Moral Good and Evil. Physical Culture and Sport. Study and Research, 69, 21-29.

Kosiewicz, J. (2011). Foul Play in Sport as a Phenomenon Inconsistent with the Rules, yet Acceptable and Desirable. Physical Culture and Sport. Studies and Research, 52(1), 33-43.

Lickona, T. (1991). Moral development in the elementary school classroom. Handbook of moral behavior and development, 3, 143-161.

Mehrabian, A. \& Epstein, N. (1972). A Measure Of Emotional Empathy. Journal of Personality, 40(4), 525-543. 
Miller, S.C., Bredemeier, B.J.L. \& Shields, D.L.L. (1997). Sociomoral Education Through Physical Education with AtRisk Children. Quest, 49, 114-129.

Rogers, C.R. (1975). Empathic: An Unappreciated Way Of Being. The counseling psychologist, 5(2), 2-10.

Rumble, A. C., Paul A. M., Lange, V., \& Parks, C. D. (2010). The Benefits of Empathy: When Empathy May Sustain Cooperation in Social Dilemmas. European Journal Of Social Psychology, 40, 856-866.

Sevdalis, V. \& Raab, M. (2014). Empathy in Sports, Exercise, and The Performing Arts. Psychology of Sport and Exercise, 15(2), 173-179.

Sezen-Balçıkanlı, G. (2009). The Relationship Between The Fair Play Behaviors and Empathic Dispositions of Professional Soccer Players (Doctoral Dissertation, Gazi University, 2009). Dissertation Abstracts International.

Sezen-Balçıkanlı, G. (2010). The Turkish Adaptation of Multidimensional Sportspersonship Orientation Scale-MSOS: A Reliability and Validity Study. Gazi Journal of Physical Education and Sports Science, 15(1), 1-10.

Sezen-Balçıkanlı, G., \& Yıldıran, İ. (2012). Sportspersonship Orientation and Empathy: A Study of Professional Football Players. Journal of Physical Education and Sport, 12(1), 18-24.

Shields, L.L.D., \& Bredemeier, L.J.B. (1994). Chracter Development and Physical Activity. USA: Human Kinetics.

Stocks, E.L., Lishner, D.D., \& Decker, S.K. (2009). Altruism or Psychological Escape: Why Does Empathy Promote Prosocial Behavior? European Journal of Social Psychology, 39, 649-665.

Trötschel, R., Hüffmeier, J., Loschelder, D.D., Schwartz, K., \& Gollwitzer, P.M. (2011). Perspective Taking as a Means to Overcome Motivational Barriers in Negotiations: When Putting Oneself Into the Opponent's Shoes Helps to Walk Toward Agreements. Journal of Personality and Social Psychology, 101(4), 771-790.

Vischer, R. (1994). Empathy, Form, and Space: Problems in German Aesthetics, 1873-1893. In H. F. Mallgrave \& E. Ikonomou (Eds), Getty Center for the History of Art and the Humanities. Chicago: University of Chicago Press.

Wispe, L. (1990). History of the Concept of Empathy. In N. Esinberg \& J. Strayer (Eds). Empathy and Its Development (pp. 17-37). New York: Cambridge University Press,.

Yıldıran, İ. (2005). Fair Play Eğitiminde Beden Eğitiminin Rolü /The Role of Physical Education in Fair Play Education/. Gazi Beden Eğitimi ve Spor Bilimleri Dergisi, 10(1), 3-16.

AUTHOR'S ADDRESS: $\quad$ Gulfem Sezen Balcikanli

Gazi University

Depatment of Physical Education and Sports Teaching

Faculty of Sport Sciences

Teknikokullar/Besevler Ankara, Turkey

E-mail: gulfems@hotmail.com

Received: 12 December 2016; Accepted: 30 January 2017 